\title{
Dependent processing in dichotic listening as a function of word meaning attributes
}

\author{
BRIAN O'NEILL and ALLAN PAIVIO \\ University of Western Ontario, London, Ontario, Canada N6A 5 C2
}

\begin{abstract}
Single dichotic word pairs were presented for immediate identification. Recognition probability was greater and response latencies shorter for high- than for low-frequency words. Both recognition measures were also affected by the frequency of the word accompanying the target word, performance being facilitated by a high-frequency partner and sometimes impaired by a low-frequency partner. Associative meaningfulness had similar, though less reliable, effects whereas the effects of word concreteness-abstractness were inconsistent. Recognition accuracy was generally superior for right-ear inputs, but recognition latency did not show consistent ear effects. Similar results were obtained under both unrestricted (Experiment 1) and controlled (Experiment 2) ear order of report instructions. The findings are consistent with a limited capacity interpretation of secondary processing in word perception.
\end{abstract}

When two different verbal stimuli are presented simultaneously, one to each ear of a listener, they are usually difficult to recognize. At least part of the difficulty is due to a mutual occlusion of the two incoming signals as they compete for access to primary speech encoding areas in the left hemisphere (see Kimura, 1961, Note 1). If coding at this primary level is successful, however, recognition could be affected by subsequent interactions between the two stimuli in the course of secondary processing. Presumably, such interactions would depend on the capacity of the stimuli to activate higher level coding processes that influence word recognition. This was explored in the present investigation.

The verbal stimulus attributes that have been most widely investigated in perceptual recognition studies include the estimated frequency of occurrence or familiarity value of a word, its associative meaningfulness value, and the concreteness-abstractness of the thing named by a word. Relevant findings are summarized elsewhere (Paivio, 1971; Paivio \& O'Neill, 1970). The influence of these attributes on word identification has been investigated in two dichotic listening studies, one by Dodwell (1964), in which frequency and meaningfulness were systematically varied, and the other by Borkowski, Spreen, and Stutz (1965), in which the concreteness-abstractness of stimulus words was varied. Dodwell found that common

Some of the results reported here appeared originally in a doctoral dissertation by the first author under the supervision of the second author at the University of Western Ontario. The research was supported by a grant to the second author from the National Research Council of Canada (A0087). Helpful criticisms of an earlier draft of this paper were obtained from Zenon Pylyshyn, Rob Rodensky, and John te Linde. Reprints may be obtained from Brian O’Neill, Personnel Psychology Center, 300 Laurier Avenue, L'Esplanade Laurier, Ottawa, Ontario, Canada K1A 0M7. words were identified more often than the uncommon words with which they were paired, and similarly, recognition was superior for words high in associative meaningfulness than for their low association value partners. Borkowski et al. (1965) likewise obtained higher scores for concrete than for abstract words. It is not clear from these findings whether a particular attribute affected the ease with which simultaneous stimuli could be identified or whether it affected recall of the stimuli once heard. Since, in the Dodwell experiments, the order of reporting items was not controlled, the observed attribute effects might have occurred only with items reported second and, consequently, reflect memory rather than perceptual recognition processes. A short-term memory factor might likewise be responsible for the stimulus attribute effect in the Borkowski et al. study, inasmuch as each experimental trial involved a relatively high memory load of three word pairs. Given that word concreteness exerts a significant positive influence on short-term recall (e.g., Paivio \& Smythe, 1971) but an unreliable effect on perceptual recognition (see Paivio \& O'Neill, 1970), a memory interpretation of this result would seem to be most appropriate.

The present investigation sought to resolve these issues by studying dichotic recognition performance under conditions of reduced memory load and a controlled order of report. Under such conditions, it was reasoned, factors affecting perceptual processing should make a significant contribution to performance. Given that an attribute is influential, a question of theoretical interest is whether the probability of recognizing one of the words is affected by the value of its dichotic partner on the same attribute. Should one member of a word pair be easy to encode by virtue of its attribute value, extra processing resources might thereby be made available to its partner, thus increasing the 
probability of the latter being recognized. This hypothesized higher order dependence between verbal stimuli presupposes a limited processing capacity that must be distributed over the two inputs (see, for example, Kahneman, 1973; Massaro, 1975; Mewhort, Thio, \& Berkenmeyer, 1971). On the other hand, it is equally plausible to suppose that capacity is unlimited at the critical levels of lexcial encoding affected by the above stimulus attributes. According to Norman (1968), for instance, higher order lexical representations of simultaneous stimulus inputs are aroused simultaneously with unlimited resources being available for this purpose. An implication of this second alternative is that, with suitable experimental procedures for minimizing the problem of remembering the input items and deciding which should be processed or reported first, recognition of one item should remain essentially unaffected by the secondary properties of its partner.

Data reported by Dodwell (1964) are relevant to the dependent-independent question as it pertains to the frequency attribute. His stimulus pairs consisted of a very high-frequency word paired with another word selected from the extremely rare $\left(1\right.$ in $\left.4 \times 10^{6}\right)$ to low $\left(10\right.$ in $\left.10^{6}\right)$ frequency range. The probability of the uncommon word being recognized was found to increase as its own frequency value increased; moreover, recognition of the high-frequency word remained uniformly high regardless of the frequency value of its partner. While this suggests that each of the words is processed independently of the frequency of the other word, the incomplete design of Dodwell's experiment does not allow an adequate test of the dependent processing hypothesis. Such a test requires comparisons between high-frequency words in mixed (high-low) and in unmixed (high-high) pairs, as well as between low-frequency words in mixed (high-low) and unmixed (low-low) pairs. According to the independence position, recognition probability should not differ for words of like attribute value belonging to mixed as opposed to unmixed pairs. The dependence hypothesis, by contrast, predicts significant differences between likevalue words according to the type of pair they belong to. Thus, words paired with high-value partners should be recognized better than like words paired with lowvalue partners. There are no available data concerning the probability of recognizing a word in relation to the meaningfulness or concreteness of its partner; however, the same design logic applies equally well to those attributes.

A further question addressed by the present investigation concerns the effect of each of the stimulus attributes on the ear asymmetry that is typically found for verbal material in the dichotic listening task. Numerous studies have shown that verbal material presented to the right ear is reported more accurately than verbal material to the left ear (see Krashen, 1976). According to Kimura (1961, Note 1), right-ear inputs receive an advantage early in the analysis of the speech code because the neural pathways between right ear and the dominant left hemisphere are more efficient than the ipsilateral ones between left ear and left hemisphere. The relationship of various dimensions of stimulus meaning to ear asymmetry has been a topic of interest in a number of dichotic listening studies (e.g., Borkowski et al., 1965). According to the position taken above, a recognition superiority for right-ear inputs should be found whatever the attribute values of the incoming words. Assuming, first, that ear asymmetry occurs at a primary coding level and, second, that the processes coordinated with the word attributes can only be elicited after primary processing is complete, it follows that any effect due to the ear of input should be independent of attribute effects.

Two dependent measures were taken in the following experiments. The number of words correctly identified was the primary performance measure, and, as a secondary measure, the time taken to make an identification was also recorded. Experimental instructions emphasized the accuracy criterion without alluding to the time measure, hence the latter is somewhat different from typical measures of processing speed. Its chief significance lies in providing subsidiary evidence that might confirm critical results obtained with the accuracy scores. Experiments 1 and 2 differed in that the order of report was unrestricted in the former but controlled in the latter.

\section{EXPERIMENT 1}

\section{Method}

Stimulus materials. Three sets of 96 nouns each were selected from the Paivio, Yuille, and Madigan (1968) norms. Each set consisted of 48 words that were high and 48 that were low in one of the following attributes: rated concreteness, associative meaningfulnes (Nobel's, 1952, production $\mathrm{m}$ index), and Thorndike-Lorge frequency. The other attributes were held constant within the constraints imposed by the size of the available word population. In all cases, rated imagery and rated concreteness were allowed to covary. The nouns thus selected were paired such that each set included an equal number $(\mathrm{n}=12)$ of high-high, high-low, low-high, and low-low pairs with high and low referring to the value on the attribute that was independently varied. The words of a pair were matched for number of syllables and stress pattern and, as far as possible for attributes other than the one being manipulated. Table 1 shows that the nonvaried attributes, including syllable number, were held fairly constant at intermediate values within sets One exception is the frequency values of the words in the sets in which meaningfulness and concreteness were independently varied. For those sets it was necessary to sample words from a broad range of frequency values in order to satisfy the various selection criteria. However, the frequency distributions of the various pair conditions within these sets were equated, and words within pairs were matched for frequency.

Apparatus. The stimulus words were tape recorded by a male speaker. A dichotic tape was then made for each stimulus set with the word pairs of all the various high-low permutations occurring at a 15-sec rate, and in a randomly determined order. In order to measure recognition response times, an inaudible pulse was recorded on tape, at the onset of each word pair using a Philips Synchronizer. During testing this pulse triggered an electric clock timer (Meylan Model S-1-P), which could be 
Table 1

Attribute Means for Stimulus Word Lists

\begin{tabular}{|c|c|c|c|c|c|c|c|c|c|c|c|c|c|c|c|c|c|}
\hline \multirow{3}{*}{$\begin{array}{l}\text { Pair } \\
\text { Type }\end{array}$} & \multicolumn{6}{|c|}{ Frequency-Varied List } & \multicolumn{6}{|c|}{ Meaningfulness-Varied List } & \multicolumn{5}{|c|}{ Concreteness-Varied List } \\
\hline & \multicolumn{2}{|c|}{$\mathrm{F}^{*}$} & \multicolumn{2}{|c|}{$\mathbf{M}$} & \multicolumn{2}{|c|}{$\mathrm{C}$} & \multicolumn{2}{|c|}{$F^{*}$} & \multicolumn{2}{|c|}{ M } & \multicolumn{2}{|c|}{ C } & \multicolumn{2}{|c|}{$\mathrm{F}^{*}$} & $\mathbf{M}$ & \multicolumn{2}{|c|}{ C } \\
\hline & Mean & SD & Mean & SD & Mean & SD & Mean & SD & Mean & SD & Mean & SD & Mean & SD & Mean SD & Mean & SD \\
\hline $\begin{array}{l}\text { High } \\
\text { High }\end{array}$ & & & & & & & & & & $\begin{array}{r}.42 \\
19\end{array}$ & & $\begin{array}{r}.73 \\
1.15\end{array}$ & & & $\begin{array}{ll}6.60 & .68 \\
6.79 & 52\end{array}$ & & 20 \\
\hline $\begin{array}{l}\text { High } \\
\text { Low }\end{array}$ & $\begin{array}{r}54.17 \\
4.75\end{array}$ & $\begin{array}{r}13.82 \\
2.65\end{array}$ & $\begin{array}{l}5.57 \\
5.49\end{array}$ & $\begin{array}{l}.81 \\
.81\end{array}$ & $\begin{array}{l}3.05 \\
3.24\end{array}$ & $\begin{array}{l}1.12 \\
1.15\end{array}$ & $\begin{array}{l}36.25 \\
39.08\end{array}$ & $\begin{array}{l}33.67 \\
38.06\end{array}$ & $\begin{array}{l}6.58 \\
4.58\end{array}$ & $\begin{array}{l}.33 \\
.49\end{array}$ & $\begin{array}{l}3.47 \\
3.44\end{array}$ & $\begin{array}{l}1.59 \\
1.56\end{array}$ & $\begin{array}{l}50.66 \\
49.75\end{array}$ & $\begin{array}{l}38.11 \\
38.96\end{array}$ & $\begin{array}{ll}5.60 & .62 \\
5.61 & .47\end{array}$ & $\begin{array}{l}6.59 \\
2.97\end{array}$ & $\begin{array}{l}.31 \\
.87\end{array}$ \\
\hline $\begin{array}{l}\text { Low } \\
\text { High }\end{array}$ & $\begin{array}{r}4.83 \\
66.67\end{array}$ & $\begin{array}{r}3.87 \\
23.57\end{array}$ & $\begin{array}{l}5.32 \\
5.42\end{array}$ & $\begin{array}{l}.77 \\
.83\end{array}$ & $\begin{array}{l}2.97 \\
2.97\end{array}$ & $\begin{array}{l}1.57 \\
1.55\end{array}$ & $\begin{array}{l}29.50 \\
34.33\end{array}$ & $\begin{array}{l}25.72 \\
33.34\end{array}$ & $\begin{array}{l}4.78 \\
6.39\end{array}$ & $\begin{array}{l}.93 \\
.66\end{array}$ & $\begin{array}{l}3.61 \\
3.89\end{array}$ & $\begin{array}{l}1.63 \\
1.13\end{array}$ & $\begin{array}{l}48.50 \\
45.41\end{array}$ & $\begin{array}{l}38.18 \\
34.09\end{array}$ & $\begin{array}{ll}5.76 & .56 \\
5.90 & .72\end{array}$ & $\begin{array}{l}2.23 \\
6.83\end{array}$ & $\begin{array}{l}.72 \\
.18\end{array}$ \\
\hline $\begin{array}{l}\text { Low } \\
\text { Low }\end{array}$ & $\begin{array}{l}3.25 \\
3.00\end{array}$ & $\begin{array}{l}2.62 \\
2.12\end{array}$ & $\begin{array}{l}4.90 \\
4.93\end{array}$ & $\begin{array}{l}1.04 \\
1.08\end{array}$ & $\begin{array}{l}3.35 \\
3.39\end{array}$ & $\begin{array}{l}1.49 \\
1.54\end{array}$ & $\begin{array}{l}37.25 \\
36.08\end{array}$ & $\begin{array}{l}31.42 \\
31.92\end{array}$ & $\begin{array}{l}4.89 \\
4.69\end{array}$ & $\begin{array}{l}.19 \\
.31\end{array}$ & $\begin{array}{l}3.75 \\
4.29\end{array}$ & $\begin{array}{l}1.31 \\
1.51\end{array}$ & $\begin{array}{l}48.33 \\
48.91\end{array}$ & $\begin{array}{l}39.29 \\
38.74\end{array}$ & $\begin{array}{ll}5.51 & .54 \\
5.50 & .45\end{array}$ & $\begin{array}{l}3.19 \\
3.28\end{array}$ & $\begin{array}{r}1.01 \\
.94\end{array}$ \\
\hline
\end{tabular}

Note $-F=$ frequency; $M=$ meaningfulness; $C=$ concreteness.

*Values of 100 and 50 were assigned to $A A$ and $A$ counts, respectively.

stopped by the experimenter as soon as the subject uttered his first response. This procedure was adopted because earlier attempts to record reaction times using a throat microphone as a trigger proved to be unreliable owing to anticipatory vocalizations by some subjects as they attempted to identify the stimuli. In order to obviate ceiling effects in recognition performance, an appropriate volume level was determined preexperimentally, using pilot subjects. Both channels of the tape recorder were matched for subjective loudness before testing sessions began. A Sony TC230 tape recorder and Sharpe HA 10 headphones were used to present the dichotic pairs.

Subjects and Procedure. The subjects were 48 undergraduate students (24 males, 24 females), the majority of whom participated in the experiment as a requirement for an introductory course in psychology. They ranged between 17 and 26 years of age. According to self-reports, all were right-handed and had no known hearing difficulties. Sixteen subjects heard the pairs from one of the three attribute-varied sets. The set that a particular subject heard was randomly determined according to the order of his or her appearance at the laboratory. Headphones were reversed for alternate subjects to counterbalance any differences in quality between the two channels of the tape recorder.

Each subject was tested individually after listening to instructions read by the experimenter. On every trial, the subject was to report the two words as soon as they were presented and he was encouraged to respond even if not completely sure about the identity of the words he had heard. The experimenter checked his responses on an answer sheet and recorded the ear order of report, the response time, and any intrusions that had occurred.

\section{Results}

The principal dependent measure was the number of words correctly identified. These were analyzed in a 2 by 2 by 2 design in which the main factors were: ear of presentation (right vs. left), attribute (high vs. low), and homogeneity (homogeneous vs. heterogeneous or mixed). Homogeneity refers here to the attribute level of one word in a pair relative to the attribute level of its partner. In each cell the possible score is 12 . The second dependent measure, recognition response time, was determined by considering only those pairs in which both of the words had been correctly identified by the subject. The recognition time applied only to the first word reported. For purposes of analysis, mean recognition time, averaged over pairs that qualified, constituted a dependent score. A subject contributed eight such scores, one for each of the pair type by ear order of report conditions. Average response times for individual pairs were also computed. Recognition response time differences among pair types (high-high vs. high-low vs. low-high vs. low-low) were tested by simple analysis of variance and between ear of report (right ear first vs. left ear first) by $t$ test.

Recognition scores for frequency-varied, concretenessvaried, and meaningfulness-varied pairs were analyzed separately, treating words (or pairs) as well as subjects as random effects and computing min $\mathrm{F}^{\prime}$ values where appropriate. 'The alpha level for $\min \mathrm{F}^{\prime}$ was set at 10\%. Accuracy scores are summarized in Table 2.

Frequency. Accuracy scores were significantly higher for high-frequency than for low-frequency words $\left[\min F^{\prime}(1,197)=6.69, p<.025\right]$, but this effect was qualified by an interaction with the homogeneity factor $\left[\min \mathrm{F}^{\prime}(1,106)=2.79, \mathrm{p}<.10\right.$ ] (see Figure 1). Analysis of simple main effects revealed a significant superiority of high-frequency words in the homogeneous condition $(p<.01)$, but not in the heterogeneous condition. As predicted from a dependence hypothesis,

Table 2

Proportions of Words Identified in Experiment 1

\begin{tabular}{cllll}
\hline & $\begin{array}{c}\text { Ear of } \\
\text { Pair }\end{array}$ & \multicolumn{3}{c}{ Attribute Varied } \\
\cline { 4 - 5 } Pype & tation & $\mathrm{F}$ & $\mathrm{M}$ & $\mathrm{C}$ \\
\hline High & Right & .88 & .91 & .94 \\
High & Left & .83 & .77 & .82 \\
High & Right & .83 & .83 & .84 \\
Low & Left & .70 & .76 & .79 \\
Low & Right & .80 & .84 & .90 \\
High & Left & .76 & .94 & .75 \\
Low & Right & .71 & .77 & .83 \\
Low & Left & .57 & .56 & .73 \\
\hline
\end{tabular}

Note $-F=$ frequency $: M=$ meaning fulness; $C=$ concreteness. 


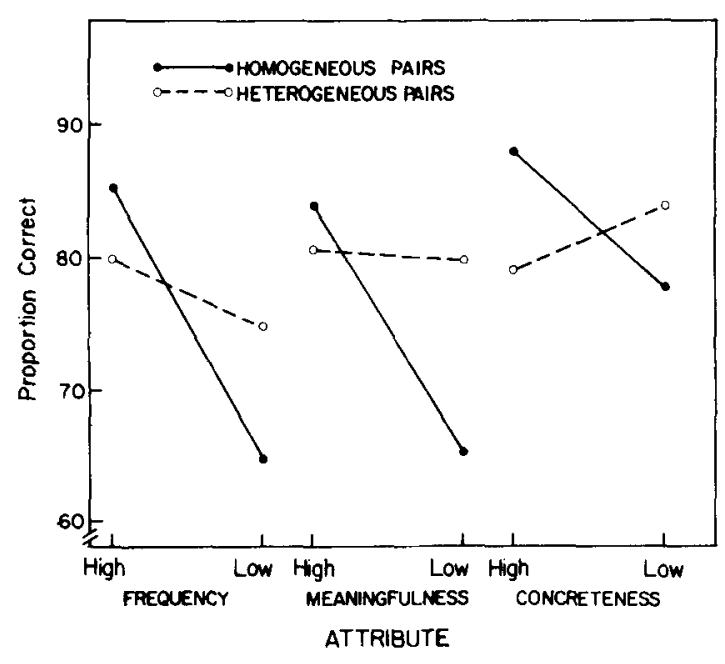

Figure 1. Proportion of words identified as a function of attribute and pair homogeneity (Experiment 1).

subjects identified high-frequency words better in homogeneous than in mixed pairs $(\mathrm{p}<.01)$ and lowfrequency words better in mixed than in homogeneous pairs $(p<.001)$. The generality of this result is limited, however, inasmuch as scores for items in mixed as compared to homogeneous pairs showed considerable overlap (for high-frequency words, $\mathrm{F}=.92, \mathrm{MSe}=5.03$; for low-frequency words, $F=2.57, \mathrm{MSe}=15.84$ ).

Recognition latencies were also related significantly to the particular attribute by homogeneity combinations represented by the pair types $\left[\min \mathrm{F}^{\prime}(3,74)=2.88\right.$, $p<.05$ ]. The ordering of the latency means is fully consistent with the interpretation that processing difficulty increased as the combined frequency value of the two paired words decreased: Low-frequency pairs took longest to identify (mean $=1.88 \mathrm{sec}$ across subjects), followed by mixed pairs (mean $=1.72 \mathrm{sec}$ ), and then high-frequency pairs (mean $=1.59 \mathrm{sec}$ ).

Accuracy scores were significantly higher for right-ear $(81 \%)$ than for leftear words $(72 \%)$ $\left[\min F^{\prime}(1,22)=4.14, p<.10\right]$. Response latencies, moreover, were shorter for rightear (mean $=1.69 \mathrm{sec}$ ) than for left-ear $($ mean $=1.83 \mathrm{sec}$ ) inputs, although this difference generalized only across stimuli $[t(43)=2.31$, $\mathrm{p}<.05]$ and not across subjects $(\mathrm{t}=.37)$. No significant interaction effect involving the ear of presentation was found.

Meaningfulness. Analysis of accuracy scores yielded a significant positive effect of the meaningfulness attribute $\left[\min F^{\prime}(1,107)=5.43, p<.025\right]$. This effect was qualified by an interaction with pair homogeneity [min $F^{\prime}=3.38, p<.10$ ] (see Figure 1). Tests of simple effects showed superior recognition accuracy for highthan for low-meaningfulness words in the homogeneous condition $(p<.01)$, but not in the heterogeneous condition. High-meaningfulness words were identified equally well under heterogeneous and homogeneous conditions; however, low-value words were identified more accurately in the heterogeneous condition $(p<.05)$. Consistent with a dependence hypothesis, this result shows that the positive effect of meaningfulness on the recognition of a given word depended on the meaningfulness of both words in the pair.

As with word frequency, the ordering of mean recognition times suggests that subjects experienced the greatest difficulty with low-low pairs $($ mean $=1.82 \mathrm{sec})$ and least difficulty with high-high pairs (mean $=1.75 \mathrm{sec}$ ), with mixed pairs (mean $=1.81 \mathrm{sec}$ ) being of intermediate difficulty. However, the analyses of response times for the various pair types yielded nonsignificant results ( $F<1$ in both analyses).

The separation of attribute and ear effects was rather less clear in the case of the meaningfulness variable as indicated by a reliable Ear by Homogeneity interaction $\left[\min F^{\prime}(1,92)=3.63, p<.10\right]$, which qualified a main effect of ear of presentation $\left[\min \mathrm{F}^{\prime}(1,31)=9.19\right.$, $p<.005$ ]. Tests of simple effects showed a reliable right-ear superiority ( $84 \%$ vs. $67 \%$ ) with homogeneous pairs $(\mathrm{p}<.001)$; with heterogeneous pairs, however, the right-ear advantage ( $84 \%$ vs. $76 \%$ ) was reliable over items $(\mathrm{p}<.05)$, but not over subjects.

Subjects took more time to respond to left-ear inputs than to right-ear inputs (respective mean values are 1.91 and $1.78 \mathrm{sec}$ ), but this difference failed to reach an acceptable significance level.

Concreteness. Main effects of concreteness and homogeneity/heterogeneity were nonsignificant, but their interaction was significant $\left[\min F^{\prime}(1,107)=3.08\right.$, $\mathrm{p}<.10]$. All tests of simple effects were found to be significant at least at the $5 \%$ level in the analysis of accuracy scores over subjects, but none of these effects was reliable across items. For the set of words used in this experiment, subjects could apparently recognize concrete words paired with other concrete words more easily than abstract words paired with abstract words. Mixed pairs, by contrast, produced a completely reversed relationship, abstract words now receiving higher scores than concrete words (see Figure 1). Time taken to make a response tended to increase for pairs containing one or more abstract words, but there was no statistical difference among their means.

Words heard in the right ear were identified more accurately than those heard in the left ear $\left[\min \mathrm{F}^{\prime}(1,29)=7.67, \mathrm{p}<.01\right]$; however, there was no reliable difference in response latency between the ears.

Because there had been some difficulty in holding frequency constant while varying meaningfulness and concreteness, subsidiary analyses were conducted on sublists of items controlled for rated familiarity. Without referring to dependent scores, items were selected according to normative familiarity values that had become available after the present experiments had been completed. These values were obtained using a 7-point rating scale, on which 7 signified high 
familiarity and 1 low familiarity. Mean rated familiarity for the meaningfulness-varied sublists were 5.77 for high-homogeneous, 5.96 for high-heterogeneous, 5.71 for low-homogeneous, and 5.81 for low-heterogeneous words. For the concreteness-varied sublists, the corresponding mean values were $6.28,5.99,5.96$, and 6.00. In all cases, each sublist comprised six word pairs. Answer sheets were rescored, counting only responses to words appearing in the new sublists. These accuracy scores were subjected to analysis of variance with experimental subjects as the random effect and all experimental effects having 1 and 15 degrees of freedom.

The results of this new analysis differed very little from the original as far as the critical interaction was concerned. For meaningfulness-varied sublists, the effects of homogeneity $(\mathrm{F}=5.74, \mathrm{p}<.05)$, and Homogeneity by Attribute $(\mathrm{F}=21.83, \mathrm{p}<.001)$ were significant. With homogeneous pairs, the attribute difference was highly significant $(F=23.20, p<.001)$, but not with heterogeneous pairs $(F=3.71)$. For the concreteness-varied sublists, the Homogeneity by Attribute interaction provided the only significant effect $(F=6.24, p<.05)$. The attribute difference was not significant in the heterogeneous condition and only marginally so in the homogeneous condition $(F=3.88, p<.10)$. These results indicate that the influence of meaningfulness on dependent processing is not attributable to uncontrolled familiarity. They suggest also that the direct and indirect effects of stimulus concreteness are weak and of low reliability.

\section{Discussion}

These results support a dependent processing position. Words that are high in frequency or meaning. fulness appear to be more easily identified than words low on those attributes, but these effects do not depend simply on the attribute value of the target words; the attribute values of the words with which they are paired also determine whether or not they will be recognized.

The recognition time data provided confirmatory evidence concerning the relationship between the frequency attribute and processing difficulty. Even when they were successfully identified, low-frequency words apparently required more time to process than highfrequency words. The finding that mixed pairs required an intermediate amount of processing time is consistent with the interpretation that residual time left over after a high-frequency word has been processed can be assigned to the low-frequency word and thereby facilitate its recognition. Processing time appears to be similarly related to the meaningfulness values of paired words but, in view of the lack of statistical significance, this relationship is merely suggestive. An important reason for controlling ear order of report in Experiment 2 was to obtain a more stable measure of recognition latency so that the reliability of these relations could be ascertained.

Of the three stimulus variables under investigation, the concreteness attribute was least reliably related to dichotic word recognition. The results in fact were quite contradictory in that concreteness had a negative as well as a positive effect on recognition accuracy, with these effects being limited to the particular words sampled. No reliable relationship was found, furthermore, between this attribute and response times. Little confidence can be placed then, in the concreteness attribute as a determinant of dichotic word discrimination. This suggests that the significant effect observed by Borkowski et al. (1965) was due to a memory rather than a recognition factor.

The final finding of interest is the consistently superior recognition of words heard in the right ear. This replicates a similar finding by Dirks (1964) using single word pairs. The ear asymmetry effect is, for the most part, statistically independent of effects involving attributes, which is consistent with the position that ear asymmetry and word attributes affect nonoverlapping levels of processing. This generalization is, of course, somewhat qualified by an apparent interdependence between the homogeneity/heterogeneity of meaningfulness-varied pairs and the factor of ear of presentation, although the reliability of this interaction remains to be seen.

\section{EXPERIMENT 2}

Experiment 2 was conducted primarily as a second test of the dependent-independent processing question. In order to further reduce the influence of short-term memory factors as well as the demands on decision making, the order of reporting the stimulus words was experimentally controlled. If interstimulus dependence is determined by factors affecting stimulus coding rather than subsequent intervening processes, the same Attribute by Homogeneity interaction effects should be found both with items reported first and with items reported second. If, conversely, the dependence is determined by processing events that are subsequent to stimulus coding, then we might expect to find these interactions with items reported second but not with those reported first. This reasoning follows from the assumption that items reported second are held in some holding mechanism and require additional processing that is not required by items reported first. It could be argued that stipulating in advance the order of reporting incoming stimuli itself constitutes an additional memory requirement. This might be considered a serious problem if the order had been varied from one trial to the next. But, given a constant order of reporting over all 48 trials, this stipulation seems unlikely to impose very much in the way of additional memory load. 


\section{Method}

Materials and procedure were identical to those of Experiment 1 with the following exceptions. Each of 24 subjects heard the words of a single pair set in the same manner as before, but this time 12 subjects were instructed at the start of the experiment to report the word heard in the right ear first on all presentations, while the remaining subjects received instructions to report left-ear inputs first. If a subject was unable to detect the item presented to the ear identified as the immediate channel, he was to say "nothing" and then report the word heard in the delayed channel. Should neither word be recognized, the response of "nothing-nothing" was to be given. As the subjects of Experiment 1 had reported that the $15-\mathrm{sec}$ recall interval was too long, the presentation rate in Experiment 2 was reduced to $10 \mathrm{sec}$. A total of 72 subjects ( 33 males and 39 females) from the same population as before participated in Experiment 2. None had taken part in the previous experiment. The design was the same as in Experiment 1 except for the additional factor of ear order of report instructions. On this occasion both the dependent measures were analyzed by means of three-way analyses of variance.

\section{Results}

Order of report reversal errors occurred on less than $4 \%$ of the trials of any list, indicating that subjects had little difficulty in conforming to the order of report instructions. Accuracy scores are summarized in Table 3.

Frequency. As in the preceding experiment, higher accuracy scores were obtained for right-ear words $(81 \%)$ than for left-ear words $(70 \%)\left[\min F^{\prime}(1,31)=5.53\right.$, $\mathrm{p}<.05$ ] and for high-frequency words than for lowfrequency words $\left[\min \mathrm{F}^{\prime}(1,107)=8.83, \mathrm{p}<.01\right]$. As before, the latter effect was qualified by an interaction involving the homogeneity factor $\left[\min \mathrm{F}^{\prime}(1,107)=2.93\right.$, $p<.10]$. Significant effects were also found for the Ear by Attribute by Homogeneity interaction [min $\left.F^{\prime}(1,114)=5.52, p<.05\right]$ and, with subjects as the random effect, for the Ear by Attribute by Homogeneity by Order of Report interaction $[F(1,22)=5.78$, $\mathrm{p}<.05]$. The four-way interaction, illustrated in Figure 2, is perhaps the more informative of these two complex effects. From this figure, it can be seen that the task of reporting right-ear words immediately following presentation enhanced recognition of the high-frequency words belonging to mixed pairs. As a consequence,

Table 3

Proportions of Words Identified in Experiment 2

\begin{tabular}{|c|c|c|c|c|}
\hline \multirow{2}{*}{$\begin{array}{l}\text { Pair } \\
\text { Type }\end{array}$} & \multirow{2}{*}{$\begin{array}{c}\text { Ear of } \\
\text { Presen- } \\
\text { tation }\end{array}$} & \multicolumn{3}{|c|}{ Attribute Varied } \\
\hline & & $\mathrm{F}$ & $\mathbf{M}$ & $\mathrm{C}$ \\
\hline $\begin{array}{l}\text { High } \\
\text { High }\end{array}$ & $\begin{array}{l}\text { Right } \\
\text { Left }\end{array}$ & $\begin{array}{l}.85 \\
.78\end{array}$ & $\begin{array}{l}.87 \\
.83\end{array}$ & $\begin{array}{l}.91 \\
.89\end{array}$ \\
\hline $\begin{array}{l}\text { High } \\
\text { Low }\end{array}$ & $\begin{array}{l}\text { Right } \\
\text { Left }\end{array}$ & $\begin{array}{l}.92 \\
.76\end{array}$ & $\begin{array}{l}.81 \\
.74\end{array}$ & $\begin{array}{l}.80 \\
.85\end{array}$ \\
\hline $\begin{array}{l}\text { Low } \\
\text { High }\end{array}$ & $\begin{array}{l}\text { Right } \\
\text { Left }\end{array}$ & $\begin{array}{l}.81 \\
.76\end{array}$ & $\begin{array}{l}.84 \\
.77\end{array}$ & $\begin{array}{l}.88 \\
.80\end{array}$ \\
\hline $\begin{array}{l}\text { Low } \\
\text { Low }\end{array}$ & $\begin{array}{l}\text { Right } \\
\text { Left }\end{array}$ & $\begin{array}{l}.64 \\
.51\end{array}$ & $\begin{array}{l}.79 \\
.68 \\
\end{array}$ & $\begin{array}{l}.83 \\
.83\end{array}$ \\
\hline
\end{tabular}

Note $-F=$ frequency $M=$ meaningfulness; $C=$ concreteness.

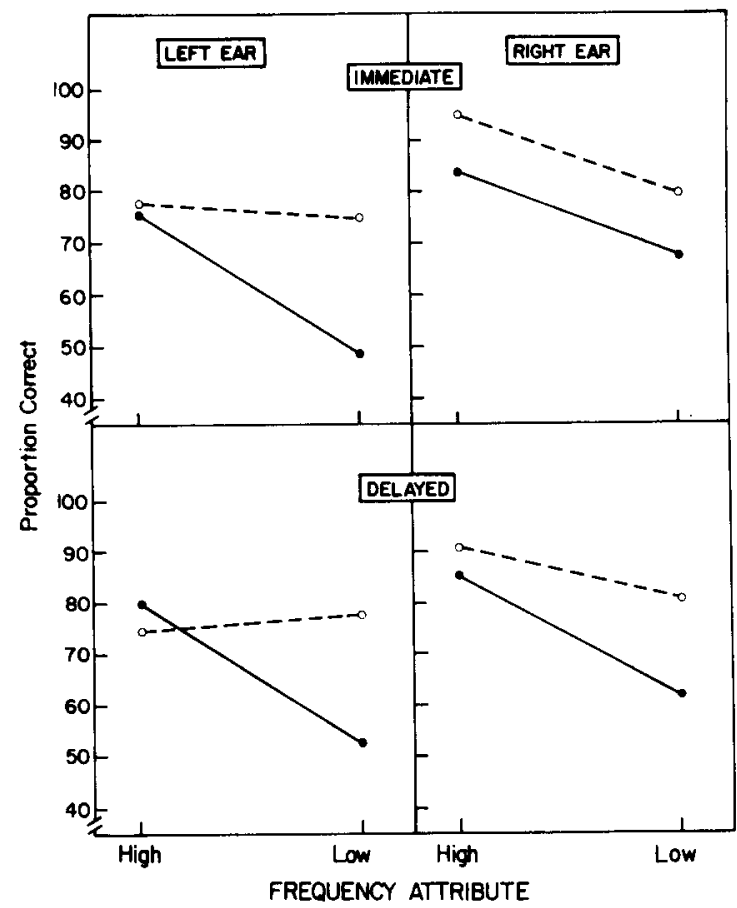

Figure 2. Proportion of words identified as a function of word frequency, ear of presentation, and report order (Experiment 2). Solid lines indicate homogeneous pairs; broken lines indicate heterogeneous pairs.

the Attribute by Homogeneity interaction fails to emerge in this one condition. The interaction is apparent, however, in the remaining three conditions, all the simple interaction effects yielding significant $F$ values $(.001 \leqslant p<.05)$. Tests of simple main effects of the frequency variable, without regard to ear of presentation or order of report, showed a highly reliable difference in the homogeneous condition $(81 \%$ vs. $57 \%)(\mathrm{p}<.001)$. In the heterogeneous condition, by contrast, the difference ( $85 \%$ vs. $78 \%$ ) was reliable across subjects $(p<.01)$, but not with words as the random effect $(F<1)$. Further analysis revealed that high-frequency words were equally well identified irrespective of the words with which they were paired, but that low-frequency words were better identified if they were paired with high- rather than with other low-frequency words $(\mathrm{p}<.005)$.

Analysis of the recognition time data yielded results in close concordance with those obtained for accuracy scores. Words heard in the right ear were responded to faster than those to the left; mean response times per word were, respectively, 2.04 and 2.14. Owing to wide individual differences among subjects, this effect was reliable only across stimulus items $[F(1,92)=30.88, p<.001]$. Highly significant effects, reliable across both subjects and words, were found for the frequency attribute $\left[\min F^{\prime}(1,91)=9.99, p<.005\right]$ and for the Attribute by Homogeneity interaction $\left[\min F^{\prime}(1,103)=12.09\right.$, 


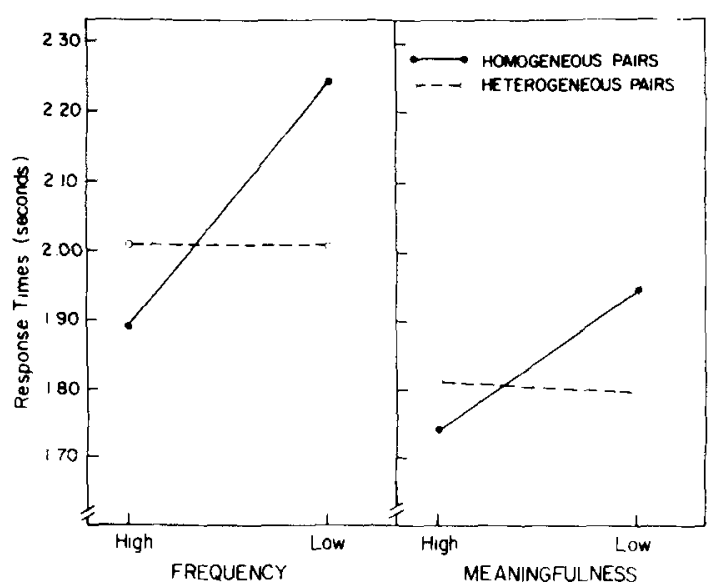

Figure 3. Mean response time as a function of frequency by homogeneity and meaningfulness by homogeneity (Experiment 2).

$\mathrm{p}<.001$ ] (see Figure 3). With the exception of the attribute effect within the heterogeneous condition, all of the simple main effects involved in this interaction, across both subjects and words, were highly reliable at least at the $1 \%$ confidence level. Specifically, the results show significantly longer recognition times for low- than for high-frequency words belonging to homogeneous pairs but no frequency effect for words in mixed pairs. Responses to both high- and low-frequency words were faster if they were paired with high-frequency words than with low-frequency words. This confirms that the time required to discriminate a word is inversely related both to the frequency of the word itself and to the frequency of the word with which it is paired. It should be noted that the interactive effect of frequency and homogeneity was quite independent of differences due to ear of presentation.

Meaningfulness. Accuracy scores for meaningfulnessvaried words revealed only two significant effects according to the min $\mathrm{F}^{\prime}$ criterion, ear of presentation $\left[\min F^{\prime}(1,35)=5.32, p<.05\right]$ and Ear of Presentation by Order of Report [min $\left.F^{\prime}(1,35)=3.23, p<.10\right]$. The instruction to report first from the left ear was found by simple effects analysis to have effectively cancelled the usual right-ear advantage but, with the reversed order of report, this advantage (86\% vs. $73 \%$ ) was quite apparent $(p<.005)$. In contrast with Experiment 1, no significant Ear by Homogeneity interaction was found. There was a tendency for the ear effect to be more pronounced with low-than with high-meaningfulness words but, although significant in the separate analyses by subjects and by items, this interaction failed to reach the $10 \%$ significance level by the $\min F^{\prime}$ criterion $\left[\min F^{\prime}(1,66)=2.63\right]$.

Accuracy scores provided only partial support for the involvement of stimulus meaningfulness in an interword dependence relationship. The critical effect, the Attribute by Homogeneity interaction, was reliable but only across subjects $[F(1,22)=4.94, p<.05]$. This interaction qualifies a main effect of attribute $[F(1,22)=19.34, \quad p<.001]$. As was found in Experiment 1, subjects reported a greater number of high - than low-meaningfulness words ( $85 \%$ vs. $73 \%)$ in the homogeneous condition $(p<.001)$, whereas in the heterogeneous condition performance was identical (79\%) for both levels of the stimulus attribute. Accuracy scores were significantly higher for highhomogeneous words than for high-heterogeneous words $(\mathrm{p}<.025)$ and, as was found previously, for lowheterogeneous words than for low-homogeneous words $(\mathrm{p}<.025)$.

By comparison with this qualified evidence for the involvement of meaningfulness in interactive processing, recognition time data yield unequivocal support. By the $\min \mathrm{F}^{\prime}$ criterion, the sole significant result to emerge from the analysis of recognition times was a reliable Attribute by Homogeneity interaction $\left[\min F^{\prime}(1,104)=4.22, p<.05\right] \quad$ (see Figure 3). For homogeneous pairs, recognition times were inversely related to meaningfulness leve] $(p<.01)$, but for heterogeneous pairs there was no significant relationship. Recognition times were marginally faster for lowmeaningfulness words that were paired with high- as opposed to other low-meaningfulness words $(p<.10)$. Recognition response times, finally, were not significantly related to ear of presentation.

Concreteness. Although some of the experimental effects were statistically reliable over subjects or words, accuracy scores failed to yield a result that approached significance according to the $\min \mathrm{F}^{\prime}$ test. Word concreteness interacted significantly with the homogeneity factor, but this was restricted to the analysis treating subjects as the random effect $[F(1,22)=26.06$, $p<.001]$. An Ear of Presentation by Order of Report interaction, with words providing the error variance $[F(1,92)=4.38, p<.05]$, indicated an order of report advantage for words heard in the right $(89 \%$ vs. $85 \%)$ but not the left ear ( $83 \%$ vs. $82 \%)$. The significance of this result lies in showing that the advantage of reporting the left-ear input first was neutralized by the superiority of the opposite ear as a receiving channel.

Contrasting with this right-ear advantage in terms of recognition accuracy, the analysis of recognition times showed significantly faster responses for left-ear (mean $=1.50 \mathrm{sec})$ over right -ear inputs (mean $=1.59 \mathrm{sec}$ ), although this finding generalizes once again only to the item population $[F(1,92)=7.02, p<.01]$. Recognition latency scores also yielded a reliable effect of homogeneity $\left[\min \mathrm{F}^{\prime}(1,113)=3.17, p<.10\right]$ due to the fact that more time was required to begin reporting homogeneous pairs (mean $=1.60$ ) than heterogeneous pairs $($ mean $=1.50)$. In accordance with the interpretation that stimulus concreteness is at best only a weak determinant of interactive processing in dichotic word perception, this effect of the homogeneity variable 
was quite independent of the attribute level of the words.

\section{Discussion}

The results of the second experiment confirm the main finding of Experiment 1. Recognition accuracy and latency scores were not determined simply by the frequency and meaningfulness of the target words, but by the attribute values of their partners as well. With frequency-varied pairs, accuracy scores showed the critical interaction in three out of four experimental conditions, whereas response times showed the interaction in all conditions. The one result involving word frequency that is difficult to explain is the unexpectedly high accuracy scores obtained for highfrequency words from mixed pairs heard in the right ear and reported first. This result suggests the operation of a mechanism that assigns processing priority to highover low-frequency words, based perhaps on a preliminary analysis of structural features or letter combinations (see Rubenstein, Garfield, \& Millikan, 1970). Given such a mechanism, the various experimental conditions--the putative processing bias, rightear reception, and immediate order of report-would all combine to maximize processing of those highfrequency words. Despite this uneven distribution of the various advantages over the two inputs, however, recognition of the low-frequency words heard in the left ear and reported second did not noticeably suffer. A tentative interpretation is that the ear and order of report variables were not sensitive to the same kind of resource limitations as were the secondary properties of stimulus words.

The generality of the results pertaining to the meaningfulness attribute is somewhat less certain but, on balance, they are consistent with the interpretation that word meaningfulness, as well as frequency, results in dependent processing. It remains to be seen whether similar or different dependent processes underlie the effects of the two attributes, frequency and meaningfulness. Inasmuch as these word properties are quite distinct conceptually as well as operationally, some difference in the underlying mechanisms seems more likely than not. One possibility is that the locus of the meaningfulness effect, in comparison with the frequency effect, might be at or closer to a primary level of processing (see also Paivio \& O'Neill, 1970). In this event an interaction of stimulus meaningfulness with ear of input would not be unexpected. Although present evidence is somewhat inconsistent in this regard, it does point to such a relationship: In Experiment 1, ear asymmetry was found to vary depending on the homogeneity/heterogeneity of meaningfulness-varied pairs and, in Experiment 2, ear asymmetry tended to be greater for pairs low rather than high in meaningfulness. This evidence is obviously far from conclusive and further investigation is clearly required before the locus of meaningfulness effects in word identification is determined.

Especially interesting in the second experiment is the finding that the order of reporting the material had little effect on the dependent processing relationship. This suggests that the interstimulus dependence identified here occurs during encoding rather than at some later stage of information processing involving short-term memory and decision-making factors. A further indication that this dependence does not involve memory processes is the absence of a reliable and consistent relationship between concreteness, which is normally a reliable predictor of memory performance (see Paivio, 1971), and the dependent measures of the present task.

A question of some theoretical interest and one that deserves some comment in the present context concerns the symmetry of the interword dependence phenomenon. Some of the results seem to suggest that the extent of this dependence differs for words that are high and those that are low on an effective attribute. Thus, in Experiment 1, recognition of a low-meaningfulness word appeared to be facilitated more by being paired with a high-value word than was recognition of the latter impaired by occurring in the same pair context as a low-value word. In Experiment 2, likewise, recognition probability of high-frequency words was essentially unaffected by its partner's frequency value, whereas the probability of recognizing a low-frequency word very much depended on the frequency level of its partner. This would seem to confirm similar findings by Dodwell (1964) and to suggest that higher order stimulus dependence only influenced recognition of words that were difficult to identify. However, asymmetrical dependence is not a uniform finding; symmetrical dependency effects were also obtained, in Experiment 1 with the frequency attribute and in Experiment 2 with the meaningfulness attribute. As a possible resolution of these discrepancies, if symmetrical dependence were assumed, for the moment, to represent the true state of affairs, the observed instances of asymmetry could be attributed to a restriction of range brought about by very high levels of recognition for the high-value words.

In addition to the evidence they provide on the dependence phenomenon, the present experiments contribute substantively to the ear asymmetry literature. With the exceptions noted above, the findings involving ear of presentation and order of report are for the most part readily explained. They attest generally to the robustness of the right-ear advantage which emerged as main effects or in interactions with other factors despite reduced memory load and controlled order of reporting. Kimura's (1961, Note 1) perceptual competition interpretation most readily explains these results. Certainly, the right-ear advantage observed here cannot be accounted for by attentional or order of 
report biases favoring the right ear (see Bryden, 1967, for a review), since such biases would have been overridden by the reporting instructions. These results, finally, fail to confirm that right-ear inputs are consistently processed more rapidly than left-ear inputs (e.g., Catlin \& Neville, 1976). Indeed the opposite was found with concreteness-varied pairs even though recognition tended to be more accurate in the right than in the left ear.

In conclusion, the results reported in this paper are consistent with certain limited capacity conceptions of the word recognition process. At a primary level, they confirm the perceptual competition interpretation of ear asymmetry by Kimura (1961) and, at a secondary level, they are generally compatible with limited access models of the kind proposed by Oldfield (1966) and Rubenstein et al. (1970). The main generalization suggested by the findings is that the processing resources available for identifying a given word depend directly on certain lexical codes that the word itself arouses, and indirectly on the amount of capacity taken up by the paired word.

\section{REFERENCE NOTE}

1. Kimura, D. Functional asymmetry of the brain in perception. Research Bulletin No. 85, Department of Psychology, University of Western Ontario, 1968.

\section{REFERENCES}

Borkowski, J. G., SPreen, O., \& Stutz, J. Z. Ear preference and abstractness in dichotic listening. Psychonomic Science, $1965,3,547-548$.

BRYDEN, M. P. An evaluation of some models of laterality effects in dichotic listening. Acta Oto-Laryngologica, 1967, 63, 595-604.

Catlin, J., \& Neville, H. The laterality effect in reaction time to speech stimuli. Neuropsychologica, 1976, 14, 141-143.

DrRks, D. Perception of dichotic and monaural verbal material and cerebral dominance for speech. Acta Oto-Laryngologica, 1964, 58, 73-80.

DoDwell, P. C. Some factors affecting the hearing of words presented dichotically. Canadian Journal of Psychology, $1964,18,72-91$.
Kahneman. D. Attention and effort. Englewood Cliffs, N.J: Prentice-Hali, 1973.

KimuRA, D. Some effects of temporal-lobe damage on auditory perception. Canadian Journal of Psychology, 1961. 15, 156-165.

Krashe N, S. D. Cerebral asymmetry. In H. Whitaker \& H. A. Whitaker (Eds.), Studies in neuropsycholinguistics, New York: Academic Press, 1976.

MASSARO, D. W. Experimental psychology and information processing. Chicago: Rand McNally, 1975.

Mewhort, D. J. K., Thio, H., \& Berkenmeyer, A. C. Processing capacity and switching attention in dichotic listening. Canadian Journal of Psychology, 1971, 25, 111-129.

Noвle, C. E. An analysis of meaning. Psychological Review, 1952, 59, 421-430.

Norman, D. A. Toward a theory of memory and attention. Psychological Review, 1968, 75, 522-536.

OldFIELD, R. C. Things, words and the brain. Quarterly Journal of Experimental Psychology, 1966, 18, 340-353.

Paivio, A. Imagery and verbal processes. New York: Holt, Rinehart, \& Winston, 1971.

PaIvio, A., \& O'NeILI, B. J. Visual recognition thresholds and dimensions of word meaning. Perception \& Psychophysics, 1970, 8, 273-275.

Paivio, A., \& Smythe, P. C. Word imagery, frequency, and meaningfulness in short-term memory. Psychonomic Science, 1971, 22, 333-335.

Paivio, A., Yuille, J. C., \& Madigan, S. Concreteness, imagery, and meaningfulness values for 925 nouns. Journal of Experimental Psychology Monograph Supplement, 1968, 76(1, Part 2).

Rubenstein, H., Garfield, L., \& Millikan, J. A. Homographic entries in the internal lexicon. Journal of Verbal Learning and Verbal Behavior, 1970, 9, 487-494.

\section{NOTE}

1. To simplify reporting the results, $F$ values for the analyses by subjects and by items have been omitted; similarly, simple effects have not been reported in full. These results may be obtained upon request.

(Received for publication August 23, 1977; accepted November 30,1977 .) 